Print ISSN: 2735 - 4121 Online ISSN : 2735-413X

\title{
Nurses' Performance Regarding Caring of Patients with Angina Attack at Emergency and Critical Care Units.
}

\author{
Mariam SabryShehab1,AmalEidAbdelmoniem Shaaban2 \\ 1Lecturer of Medical- Surgical Nursing, Faculty of Nursing, Damietta University, Egypt. \\ 2Lecturer of Medical- Surgical Nursing, Faculty of Nursing, Mansoura University, Egypt.
}

\begin{abstract}
Background: Angina pectoris is considered chest pain due to insufficient coronary artery blood flow and increased myocardial oxygen demand. Stable angina is a chronic disease that can progress to unstable angina or myocardial infarction. Lifestyle modification, medications, and cardiac intervention/ cardiothoracic surgery all play a part in its management. Aim of the study: To evaluate nurses' performance regarding caring of patients with angina attack at emergency and critical care units. Subjects and method: Anexploratory descriptive design was used to conduct this study on fifty nurses who are associated with giving direct care for patients in the emergency and critical care units at Alazhar University Hospital at new Damietta city. Data were collected by using two tools: Nurses' knowledge assessment questionnaire to assess nurses' knowledge regarding angina and observational checklists to assess their practices. The resultsof the present study concluded that $70 \%$ of studied nurses had a fair level of knowledge, while $62 \%$ of them had a fair knowledge score regarding angina care. As regarding practice, $60 \%$ of the studied sample had fair level of practice. There was a significant difference between level of nurses' knowledge and their practiceconcerning care, as well as highly statistical significant difference between nurses' characteristics; qualifications, job, and years of experience and their level of knowledge regarding care of patient. This study recommended that to improve nurses' performance regarding caring of patients with anginaeducational program should be conductedcontinuously.
\end{abstract}

Keywords:Nurses' performance, care of patients, Angina. 


\section{Introduction}

The most common cause of death in the developed nations is coronary heart disease (CHD). Also, it is considered to beone of the main causes of disease burden in developing countries. In 2001, 7.3 million people worldwide died of coronary heartdisease.In the low-income, and middle-income nations three-fourths of global deaths(Gaziano, Bitton, Anand, Abrahams-Gessel, \& Murphy, 2010).

After a heavy meal, stable angina is characterized by discomfort or painepisodesin the chest, jaw,shoulder, arms, back, orepigastric region,is usually caused by physical exertion. Some patientsexperience shortness of breath without pain. Unstable angina may cause restpain or discomfort. A small number of people may experience asymptomatic ischemia, and they may experience discomfort or pain once and not relapse (Blanchard \&Murnaghan, 2010).

Lifestyle changes are the crucialportion of anginatreatment, particularlyrelated to exercise, diabetes, hypertension, diet, smoking, and psychological issues. Medical therapy used in angina treatments reduces symptoms and preventscomplications related to cardiovascular such as stroke and infarction of the myocardium. In addition to stable angina guideline, the prescription of the type of medications is recommended.(Bellchambers, Deane, \&Pottle, 2016).

Nurses play a vital role in the promotion of health by delivering health education to the patient and all general population. Knowledge about cardiac patients is about not only physiology and anatomy but also includes skills of patients' self-care management, risk factors, medications, diet,exercises, andstress(Hart,Spiva,\&Kimble,2011).Nu rses'experience,skills,information, and gradeshould be updated to have the ability to changemisconceptions of their patients regarding their status and educate them regardingproper lifestyle modifications(Chow, Chan, $\mathrm{Ho}, \& \mathrm{Ng}$, 2017).

Angina can be triggered by physical effort, emotional stress, or anxiety, eating a heavy meal, or cold weather. So the nurse should educate the patient on how to manage themselves through behavioral changes to alleviate angina symptoms; rest as soon as feel symptoms coming on, reduce and manage stress, pace yourself and take regular breaks, keep warm, and avoid eating large meals (Heart Foundation, 2018).

Aim of the study:

This study aimed to:

(1) Evaluate the level of nurses' knowledge regarding caring of patients with an angina attack.

(2) Assess the nurses' practice regarding caring of patients with an angina attack.

\section{Research questions:}

- What is the level of nurses' knowledge regarding caring of patients with an angina attack?

- What is the level of nurses' practices regarding caring of patients with an angina attack?

\section{Significant of the study}

Unstable angina, non-ST segment elevation, and myocardial infarction are usually caused by atherosclerotic coronary artery disease (CAD) which is the leading cause of cardiac death. Nursing care is vital for angina patients in emergency and critical care units. Proper management can prevent patients hospitalization

(Motahediyantabrizi,NajafiMehri 
Nurses' Performance Regarding Caring etc...

,Samiei, Einollahi, \&Babaei, 2009).Stopall exertions and rest and should be maintained until the pain subsides. Nurse should assure the patient in a supportive calm manner to decrease his anxiety and provide proper positioning (Siebens et al., 2007). Suchnursing cares assist and help to reduce patient's pain. Therefore, the study was done to assess nurse's performance regarding caring of patients with angina attack at emergency and critical care units.

\section{Subjects and Method}

Research design: Exploratory descriptive design was utilized in this study.

Setting: The current study was conducted at the emergency and critical care units at Alazhar University Hospital in New Damietta city.

Subjects:A convenience sample including all nurses (50) providing care for patients with angina attack, regardless of their years of experience or qualification at Emergency (25) and Critical Care Units(25) at Alazhar University Hospital.

Tools:

Two tools were utilized to collect the neededdata, which include:

\section{Tool (I)-Nurses' Knowledge Assessment Questionnaire:}

It was used to assess nurse's knowledge about angina. It was designed and developed by the researchers in the Arabic Language after the literature review. It consists of the following parts:

PartI: Socio-Demographic data,included information about the nurses as age, sex, level of education, and training program. The data composed of 9 close- ended questions (questions 1-9).

PartII: Nurses' knowledge related to angina as the definition of angina, causes, types of angina, clinical manifestation, and how to care for thepatient. This part is composed of 21 close and open-ended questions (question 10-30)

Part III:Contains nurses' knowledge regarding care given to patients suffering from angina including, angina can be cured, control of risk factors, position, the indication of hospitalization, investigations, treatment, nursing care, physiotherapy, and health instructions. This part is composed of 24 close and open-ended questions (question 31-54)

Scoring system of nurses' knowledge:

The total score of the knowledge part II was (78) grades and part III was (126) grades. Each correct answer was scored two (2) grades, and zero for the wrong answer or did know, the total knowledge score was classified as the following:

- Good $>75 \%$.

- Fair 50-75\%.

- Poor $\leq 50$.

Tool (II) - Observational checklists:

It was adopted and modified by the researchersafter reviewingthe related literature(Perry, Potter, \&Ostendorf, 2014; Proehl, 2009). This tool included 9 practices that were used to assess nursing practices given to patients suffering from angina attack, it contained:

- Admission checklist sheet (draping the patient, removal clothes, connect on monitor, insert cannula............) (23) steps.

- $\quad$ Taking a blood sample. (15) steps.

- Drug administration (I.V therapy). (12) steps.

- $\quad$ Sublingual medication. (10) steps .

- Oxygen therapy: mask and nasal cannula. (17) steps.

- Pulse oximetry. (9) steps.

- Assessing pain. (10) steps. 
- $\quad$ ECG. (15) steps.

- Cardiac monitoring. (11) steps. Scoring system:

Each step in the observation checklist sheet was checked as competent practice or incompetent practice. Each competent practice was given one (1) grade. Incompetent practice that was done incorrectly or missed was given zero (0). The total score of all nursing practices was 122 grades andwas classified as the following

- Good $>75 \%$.

- Fair 60-75\%.

- $\quad$ Poor $\leq 60$.

Validity and reliability of the tools

The tools were tested for the validity of the content by 5 experts; three doctors of Medical-surgical Nursing and two doctors of the Critical Care and Emergency Nursing, Faculty of Nursing - Mansoura University who reviewed the tools for relevance, applicability, and clarity, and modifications were done accordingly. Internal consistency and reliability of the tools were examined by Cronbach's Alpha that revealed $r=.85$ for the knowledge assessment questionnaire and $\mathrm{r}=.90$ for the observational checklists.

Pilot study:

The pilot study was carried out on $5(10 \%)$ nurses to assess the clarity and applicability of the tools and estimate the needed time to fill out the tools. After detection of difficulties that was arisen, omission or addition for certain items was done. Nurses in the pilot study were excluded from the final sample.

\section{Ethical considerations:}

Official permission was obtained from the Faculty of Nursing, New Damietta University, and Alazhar University Hospital director to perform the study.Signed informed consent was obtained from nurses in the study setting to conduct this study. The anonymity and confidentiality had been assured. Also, they had the right to withdraw from the study at any time.

Fieldwork:

The present study was conducted through two phases; preparatoryphase and implementation phase

\section{Preparatory phase:}

An extensive review of current and past, local and international literatureconcerning the research problem was made using articles, magazines, books, and internet searches to get acquainted with current relevant literature and also to develop the study tools.Also, obtaining official permission and carrying out the pilot study.

\section{Implementation phase:}

The study was conducted during the period started from November 2019 up to February 2020 for data collection and it passed through-

- It started by interviewing the nurses at the above-mentioned settings. The researchers started by introducing themselves to the nurses, then informing them about the purpose of the study and obtaining consent.

- At the end of each shift, the researchers met the nurses at their available time (after providing their nursing activities in the unit for their patients) from 12:40 am and 6:30 pm.

- Each nurse was individually interviewed to fulfill the knowledge assessment questionnaire in his or herareas, each interview lasted for about 30-45 minutes. Using the tool I.

- The researcherswere available 5 days weekly.

- As regards the nurses' practices, they were observed in the previously mentioned setting during their actual 
work in different shifts with angina patients. Using tool II.

\section{Statistical Analysis:}

The collected data was analyzed and tabulated using the computer SPSS (Statistical Package for Social Sciences) version 21.Qualitative variables were presented as numbers and percentages and quantitative variables were presented as mean, and stander deviation. Chisquare test and P-value (significant at 0.05) were used to estimate the statistically significant difference between nurses' characteristics, their knowledge, and practice, in addition to, the association between their knowledge and practice.

\section{Limitations of the study:}

- Lack of cooperation from the nurses during the data collection phase.

\section{Results}

SocioDemographic Characteristic of Studied Nurses illustrated in table 1: It was found that $78 \%$ of nurses were in the age group of 20-30 years with mean and stander deviation $25.9 \pm 4.7$ years. In relation to the marital status $88 \%$ of them were married. Meanwhile, sixty four percent of the sample had completed their secondary nursing school education while 32\% had Bachelor in Nursing. As regards to occupation, $68 \%$ of studied nurses were staff nurse. As well as $40 \%$ of the sample had 5-10 years' experience with mean and stander deviation6.2 \pm 3.7 years.

Total nurses' knowledge regarding angina illustrated in table 2 : It was found that $70 \%$ of studied nurses had fair level of knowledge score, while $20 \%$ had poorscore, and only $10 \%$ of them had good scoreregarding angina.

Table 3 illustrated the total nurses' knowledge regarding Angina Care: It was found that $62 \%$ of studied nurses had fair knowledge score. While 32\% had poor score and only $6 \%$ of them had good score regarding angina care.

Total nurses' practice regarding angina illustrated in Table 4: this table shows that $66 \%$ of the sample had fair practice score on admission checklist and obtaining venous blood sample. While $62 \%$ of them had poor practice score in intravenous drug administration, as well as $62 \%$ of the sample had fair practice score in cardiac monitoring.

In addition, $60 \%$ of them had poor score in oxygen administration. In relation to pulse oximetry, $80 \%$ of the studied nurses had poor practice score. As well as $46 \%$ of the sample had fair score in assessing pain. In addition, $50 \%$ of them had poor score in sublingual medication. As regarded to electrocardiogram $64 \%$ of the studied sample was had fair practices score.

Table 5: clarified the relation between total nurses' knowledge and their total practice regarding care of angina patient.

It was found that no significant statistical difference between both of nurses' level of practice and their knowledge regarding disease of angina $\left(\mathrm{X}^{2}=.481\right)$ at $\mathrm{P}$ value 0.234 .

On the other hand, it was found that there was a highly significant difference between nurses' level of practice and their knowledge regarding care $\left(X^{2}=.971\right)$ at $P$ value $<0.015$.

Relation between socio demographic characteristics of studied nurses and their total knowledge score illustrated in table 6: There was no statistical significant relation betweennurses' socio demographiccharacteristics and their level of knowledge it was found no significant statistical difference between nurses' characteristics namely age, marital status, qualifications, job, and 
years of experience, with their level of knowledge $\quad\left(\mathrm{X}^{2}=1.27, \quad .68 \& 5.18\right.$, $4.43 \& 5.07)$ respectively at $\mathrm{P}>0.05$. It was found that $81.8 \%$ of nurses who had fair level of knowledge, their age more than 30 years of age.

As regards marital status of nurses, it was observed that $70.5 \%$ of them were married and had fair level of knowledge. Regarding their qualifications, it was found that $75 \%$ of nurses who had fair level of knowledge had bachelor degree in nursing and their job was head nurse. On the other hand, majority of nurses $(90.9 \%)$ who had fair level of knowledge had 10 years of experience and more.

Table7: Relation between socio demographic characteristics of studied nurses and their total knowledge score regarding care of angina: There was no significant statistical relation between each of nurses' age andmarital status and their level of knowledge regarding care of patient $\left(X^{2}=1.20, .318\right)$ respectively at $\mathrm{P}>0.05$. While there was a highly significant statistical difference between nurses' qualifications, job, and years of experienceand their level of knowledge regarding care of patient $\left(\mathrm{X}^{2}=2.58\right.$, $2.05 \& 1.34)$ respectively at $P$ $<0.040,<0.019$ and $<0.039$.

It was found that $81.8 \%$ of nurses who had fair level of knowledge, their age more than 30 years of age. As regards marital status of nurses, it was observed that $83.3 \%$ of them were single and had fair level of knowledge

Regarding theirqualifications, it was found that $100 \%$ of nurses who had fair level of knowledge had nursing institute. As regarded to their job $81.3 \%$ of nurses who had fair level of knowledge was head nurse. On the other hand, more than three quarter of nurses $(81.1 \%)$ who had fair level of knowledge had 10 years of experience and more.

Relation between socio demographic characteristics of studied nursesand their total practice scoreillustrated in table 8: it was found that insignificant statistical difference between nurses' characteristics namely age, marital status, qualifications, job, and years of experience, with their level of practice $\left(\mathrm{X}^{2}=1.19 \& .844 \& \quad .451 \& \quad .486 \& 1.23\right)$ respectively at $\mathrm{P}>0.05$. It was found that $64.1 \%$ of nurses age range 20: 30 years were had fair level in their practice.

As regarded tomarital status $83.3 \%$ of nurses' who had fair level of practice were single. In addition, it was found that, $100 \%$ of nurses had nursing institute degree in nursing had bad level in their practices. As regarded to their job, $68.8 \%$ of nurses who had fair level of knowledge was head nurse On the other hand, more than two third of nurses $(68.4 \%)$ who had fair practice level had $0:<5$ years of experience. 
Nurses' Performance Regarding Caring etc...

\begin{tabular}{|c|c|c|}
\hline Socio Demographic Characteristic & No (50) & $\%$ \\
\hline \multicolumn{3}{|l|}{ Age groups (in years) } \\
\hline$\overline{20-}$ & 39 & $78 \%$ \\
\hline $30-$ & 11 & $22 \%$ \\
\hline$\overline{\mathrm{X}}_{ \pm} \mathrm{SD}$ & \multicolumn{2}{|c|}{$25.9 \pm 4.7$ years } \\
\hline \multicolumn{3}{|l|}{ Marital status } \\
\hline$\overline{\text { Single }}$ & 6 & $12 \%$ \\
\hline Married & 44 & $88 \%$ \\
\hline \multicolumn{3}{|l|}{ Level of education } \\
\hline Bachelor in Nursing & 16 & $32 \%$ \\
\hline Nursing Institute & 2 & $4 \%$ \\
\hline Secondary nursing school & 32 & $64 \%$ \\
\hline \multicolumn{3}{|l|}{ Occupation } \\
\hline Head nurse & 16 & $32 \%$ \\
\hline Staff nurse & 34 & $68 \%$ \\
\hline \multicolumn{3}{|l|}{ Years of experience } \\
\hline$\overline{-0-}$ & 19 & $38 \%$ \\
\hline$-5-$ & 20 & $40 \%$ \\
\hline$-10+$ & 11 & $22 \%$ \\
\hline $\mathrm{X}_{ \pm} \mathrm{SD}$ & \multicolumn{2}{|c|}{$6.2 \pm 3.7$} \\
\hline \multicolumn{3}{|c|}{ Table 2: Total Nurses' Knowledge Regarding Angina } \\
\hline Level of nurses' knowledge & No(50) & $\%$ \\
\hline Good & 5 & $10 \%$ \\
\hline Fair & 35 & $70 \%$ \\
\hline Poor & 10 & $20 \%$ \\
\hline \multicolumn{3}{|l|}{ Table 3} \\
\hline \multicolumn{3}{|l|}{ Total Nurses' knowledgeregarding Angina Care } \\
\hline Level of nurses' knowledge regarding care & No(50) & $\%$ \\
\hline Good & 3 & $6 \%$ \\
\hline Fair & 31 & $62 \%$ \\
\hline Poor & 16 & $32 \%$ \\
\hline
\end{tabular}

Table 4Total Nurses' practiceregarding Angina

\begin{tabular}{lcccccc}
\hline \multirow{2}{*}{ Variable } & \multicolumn{5}{c}{ Level of total practice } \\
\cline { 2 - 7 } & \multicolumn{2}{c}{ Good } & \multicolumn{2}{c}{ Fair } & \multicolumn{2}{c}{ Poor } \\
\cline { 2 - 7 } & No. & $\%$ & No. & $\%$ & No. & $\%$ \\
\hline Admission Checklist & 11 & $22 \%$ & 33 & $66 \%$ & 12 & $24 \%$ \\
\hline Obtaining Venous blood sample & 11 & $22 \%$ & 33 & $66 \%$ & 12 & $24 \%$ \\
\hline - Intravenous drug administration & 0 & 0 & 19 & $38 \%$ & 31 & $62 \%$ \\
\hline Oxygen administration & 3 & $6 \%$ & 17 & $34 \%$ & 30 & $60 \%$ \\
\hline - $\quad$ Pulse oximetry & 0 & 0 & 10 & $20 \%$ & 40 & $80 \%$ \\
\hline - $\quad$ Assessing pain & 7 & $14 \%$ & 23 & $46 \%$ & 20 & $40 \%$ \\
\hline - $\quad$ sublingual medication & 8 & $16 \%$ & 17 & $34 \%$ & 25 & $50 \%$ \\
\hline - $\quad$ Electrocardiogram & 2 & $4 \%$ & 32 & $64 \%$ & 16 & $32 \%$ \\
\hline$\bullet \quad$ Cardiac Monitoring & 4 & $8 \%$ & 31 & $62 \%$ & 15 & $30 \%$ \\
\hline
\end{tabular}


Mariam SabryShehab1,AmalEid et. al.

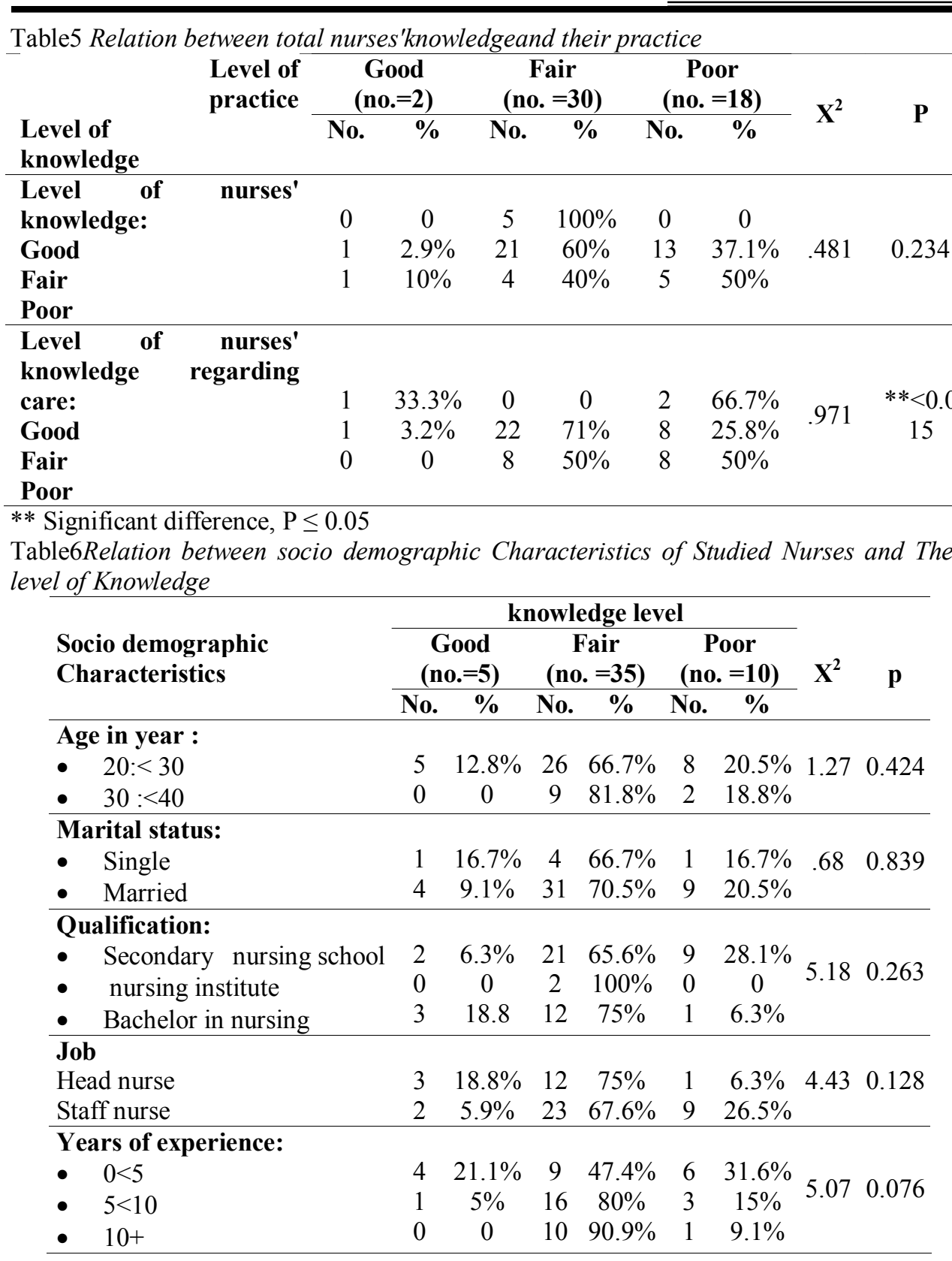


Nurses' Performance Regarding Caring etc...

Table7Relation between socio demographic characteristics of studied nurses and their total knowledge score regarding care of angina

\begin{tabular}{|c|c|c|c|c|c|c|c|c|}
\hline \multirow{3}{*}{$\begin{array}{l}\text { socio demographic } \\
\text { Characteristics }\end{array}$} & \multicolumn{6}{|c|}{ knowledge level } & \multirow{3}{*}{$\mathbf{X}^{2}$} & \multirow{3}{*}{$\mathbf{p}$} \\
\hline & \multicolumn{2}{|c|}{$\begin{array}{c}\text { Good } \\
(\text { no.=3) }\end{array}$} & \multicolumn{2}{|c|}{$\begin{array}{c}\text { Fair } \\
(\text { no. }=31)\end{array}$} & \multicolumn{2}{|c|}{$\begin{array}{c}\text { Poor } \\
(\text { no. }=16)\end{array}$} & & \\
\hline & No. & $\%$ & No. & $\%$ & No. & $\%$ & & \\
\hline \multicolumn{9}{|l|}{ Age in year: } \\
\hline - $20:<30$ & 3 & $7.7 \%$ & 22 & $56.4 \%$ & 14 & $35.9 \%$ & 1.20 & 0.275 \\
\hline - $\quad 30:<40$ & 0 & 0 & 9 & $81.8 \%$ & 2 & $18.8 \%$ & & \\
\hline \multicolumn{9}{|l|}{ Marital status: } \\
\hline - $\quad$ Single & 0 & 0 & 5 & $83.3 \%$ & 1 & $16.7 \%$ & .318 & 0.494 \\
\hline - $\quad$ Married & 3 & $6.8 \%$ & 26 & $59.1 \%$ & 15 & $34.1 \%$ & & \\
\hline \multicolumn{9}{|l|}{ Qualification: } \\
\hline - $\quad$ Secondary nursing school & 1 & $3.1 \%$ & 16 & $50 \%$ & 915 & $46.9 \%$ & & \\
\hline - $\quad$ Nursing institute & 0 & 0 & 2 & $100 \%$ & 0 & 0 & 2.58 & $* 0.040$ \\
\hline - $\quad$ Bachelor in nursing & 2 & 12.5 & 13 & $81.3 \%$ & 1 & $6.3 \%$ & & \\
\hline \multicolumn{9}{|l|}{ Job } \\
\hline Head nurse & 2 & $12.5 \%$ & 13 & $81.3 \%$ & 1 & $6.3 \%$ & 2.05 & $* *<0.019$ \\
\hline Staff nurse & 1 & $2.9 \%$ & 18 & $52.9 \%$ & 15 & $44.1 \%$ & & \\
\hline \multicolumn{9}{|l|}{ Years of experience: } \\
\hline - $5<10$ & 1 & $5 \%$ & 15 & $75 \%$ & 4 & $20 \%$ & 1.34 & $* *<0.039$ \\
\hline - $10+$ & 1 & $9.1 \%$ & 9 & $81.8 \%$ & 1 & $9.1 \%$ & & \\
\hline
\end{tabular}

** Significant difference, $\mathrm{P} \leq 0.05$

Table 8Relation betweensocio demographic Characteristics of Studied Nurses and Their Total Practice Score

\begin{tabular}{|c|c|c|c|c|c|c|c|c|}
\hline \multirow{3}{*}{$\begin{array}{l}\text { socio demographic } \\
\text { characteristics }\end{array}$} & \multicolumn{6}{|c|}{ practice level } & \multirow{3}{*}{$\mathbf{X}^{2}$} & \multirow{3}{*}{$\mathbf{P}$} \\
\hline & \multicolumn{2}{|c|}{$\begin{array}{c}\text { Good } \\
(\text { no. }=2)\end{array}$} & \multicolumn{2}{|c|}{$\begin{array}{c}\text { Fair } \\
(\text { no. }=\mathbf{3 0})\end{array}$} & \multicolumn{2}{|c|}{$\begin{array}{c}\text { Poor } \\
(\text { no. }=18)\end{array}$} & & \\
\hline & No. & $\%$ & No. & $\%$ & No. & $\%$ & & \\
\hline \multicolumn{9}{|l|}{ Age in year: } \\
\hline - $20:<30$ & 1 & $2.6 \%$ & 25 & $64.1 \%$ & 13 & $33.3 \%$ & 1.19 & 0.415 \\
\hline - $30:<40$ & 1 & $9.1 \%$ & 5 & $45.5 \%$ & 5 & $45.5 \%$ & & \\
\hline \multicolumn{9}{|l|}{ Marital status: } \\
\hline - Single & 0 & $0 \%$ & 5 & $83.3 \%$ & 1 & $16.7 \%$ & .844 & 0.449 \\
\hline - $\quad$ Married & 2 & $4.5 \%$ & 25 & $56.8 \%$ & 17 & $38.6 \%$ & & \\
\hline \multicolumn{9}{|l|}{ Qualification: } \\
\hline \multirow{3}{*}{$\begin{array}{l}\text { - } \quad \text { Secondary nursing school } \\
\text { - } \quad \text { nursing institute } \\
\text { - } \quad \text { Bachelor in nursing }\end{array}$} & 1 & $3.1 \%$ & 19 & $59.4 \%$ & 12 & $37.5 \%$ & \multirow{3}{*}{\multicolumn{2}{|c|}{$.451 \quad 0.333$}} \\
\hline & 0 & 0 & 0 & 0 & 2 & $100 \%$ & & \\
\hline & 1 & $6.3 \%$ & 11 & $68.8 \%$ & 4 & $25 \%$ & & \\
\hline \multicolumn{9}{|l|}{ Job } \\
\hline - Head nurse & 1 & $6.3 \%$ & 11 & $68.8 \%$ & 4 & $25 \%$ & .486 & 0.499 \\
\hline - $\quad$ Staff nurse & 1 & $2.9 \%$ & 19 & $55.9 \%$ & 14 & $41.2 \%$ & & \\
\hline \multicolumn{9}{|l|}{ Years of experience: } \\
\hline - $\quad 0<5$ & 1 & $5.3 \%$ & 13 & $68.4 \%$ & 5 & $26.3 \%$ & & \\
\hline - $5<10$ & 0 & 0 & 11 & $55 \%$ & 9 & $45 \%$ & 1.23 & 0.575 \\
\hline - $10+$ & 1 & $9.1 \%$ & 6 & $54.5 \%$ & 4 & $36.4 \%$ & & \\
\hline
\end{tabular}




\section{Discussion}

Angina pectoris is defined as a disease characterized by the diminished blood supply to the coronary arteries. When the patient complains pain, the nurse should teach the patient to stop exertions, rest and assume semi-fowler's position to diminish the oxygen demands of the myocardium.

The result of the current study reported that most ofnursesaged 20-30 years. Moreover, most of these nurses were married and approximately twofifth of the studied nurses had 5- 10 years of experience.These results agree withBaeez, Shakor, and Ali (2019) resultsthat most of the sample was between (20-30) years.Besides, Ibrahim, Abd-Allah, Arafa, and Mohammed,(2017) found that most of the studied participants were between 25 and 30 years old, and a significant proportion of them was married. Twothirds of them had 5-10 years of experience. Moreover, This resultconsistent with Taha (2017) who showed that the nurses were married. This result disagreed with Hamed (2009) who stated that less than half of the nurses had experience rangingfrom 2 to 4 years.

Concerning the educationallevel, the study reported that three-fifth of the studied nurses had a secondary nursing school education. This result was inconsistent with the study by Sakr, Metwaly, and Taha (2019) and Mohammed (2016), which reported that most of the studied nurses had BSc degrees in nursing.

The existing study recorded that most studied nurses had a fair level of knowledge score and the least percent had a good score regarding angina and patient's care with angina. This knowledge deficiency is due to a lack of orientation programs before working, loss of care conferences during work, lack of in-service training program, besides, no availability of critical care procedure books, and lack of supervision and nurse's evaluation regarding patient care.

On the line, Baeezetal., (2019) found in their study that the nurses have moderate knowledge regarding chest pain management and a moderate assessment of chest pain assessment. That finding was harmonious with the result by Sakretal., (2019) which showed an unsatisfactory level of nurses' knowledge pre implementing nursing intervention. Moreover, Ibrahim, etal. , (2017) found that only one-third of nurses had a satisfactory knowledge level pre-implementation of the program.

This is in line with Ahmed (2013) who reported that Cardiosurgical nursing care needs nurses with special attributes and knowledge. Moreover, it is impossible to function efficiently in such fields without acceptable professional and personal attitudes, expertise, and updated knowledge. This finding is consistent with the study by Abdelhamid (2011) which revealed that the majority of nurses had a fair level of knowledge regarding both angina disease and angina care.

Relating, total nurses' practice regarding angina; the present study showed that most of the nurses had a fair level of practice (concerning, admission checklist, obtaining a venous blood sample, cardiac monitoring, assessing pain and electrocardiogram) and a poor level of practice (regarding, intravenous drug administration, oxygen administration, pulse oximetry, sublingual medication). 
On the same line, Ibrahim, etal., (2017) found that nearly two-thirds of the studied participants had unsatisfactory practice levels preimplementation with respect to most of the nursing activities, such as performing CPR, nursing care for emergency medications, the arrangement of the emergency crash cart.

This finding agreed with ElMetwally (2012) who indicated most of the nurses had incompetent practice in the pre-program stage. Such inadequate practice is certainly related to their low level of satisfactory knowledge. Also, Abdelhamid (2011) reported that most nurses had a fair level of practice. This is consistent with the study by Drew and Krucoff (2010)which mentioned that practical skills are properly learned by guidance and strictly supervised repeated practice while treating a critically ill patient.

Collins (2001) emphasized the importance of cardiac monitoring as an important first step in the treatment program regardless of patient condition on admission, as it is an indicator of arrhythmias and it can prevent a cardiac crisis. An electronic monitoring system is a necessary component. On the same line, Mahdy (2009) revealed that the nurses had unsatisfactory practice scores before program implementation regarding 12-lead ECG and arrhythmia interpretation.

Nurses should be able to extend their knowledge through continuing education, seminars, and journals. Consequently, training programs for nurses establish a crucial element. Such programs are rigorously planned to assess how nurses improve and develop the skills needed to provide patients with a high standard of care (Ahmed,
Muhammed, Abd-Elateef, \&Ghanem, 2015).

Respecting, the relation between the total nurses' practice and their total knowledge about the care of angina patients. It was noticed that no significant statistical relation between both nurses' level of practice and their knowledge concerning the disease of angina, and there was a significant relation between the nurses' practical level and their totalknowledge about care of angina patient.

Such finding is congruent with the finding by Abdelhamid (2011) that noticed that there was a highly significant difference between nurses' knowledge level and their practicerelated care. In addition, Abdelmoaty (2009) reported that there is a significant statistical relationship between nursing knowledge and practice level.

Concerning, the relation between socio-demographic characteristics of studied nurses and their total knowledge score, it was found no significant statistical difference between nurses' characteristics with their level of knowledge. This finding was in disagreement with the study by Sakretal., (2019) which revealed that there was a statistical significant relation between age of the nurses, level of education, years of experience, and attendanceof training courses, and their satisfactory knowledge score of angina. Also, Abdelhamid (2011) reported that there was a highly statistically significant relation between characteristics of nurses(level of education, hierarchical level, and years of experience) and what they know.

Relation between sociodemographic characteristics of studied nurses and their total practice score, it was clarified that insignificant statistical 
Mariam SabryShehab1,AmalEid et. al.

difference between nurses' characteristics; age, marital status, qualifications, job, and years of experience, with their practice level.On the same line, Abdelhamid (2011) revealed that there was no statistically significant relation was found between characteristics of nurses (age, level of education, marital status, years of experience, and hierarchical level) and their level of practice. Also, the results agreed with Abdelmoaty (2009) who found that there was no statistically significant relation was found between the level of practice and experience.

This result is inconsistent with Sakretal., (2019) reported a statistical significant relation between the age of nurses, level of education, experience years, and attendance of training courses and their satisfactory practical score regarding angina.

Conclusion: The result of this study concluded that $70 \%$ of studied nurses had a fair level of knowledgeconcerning angina, while $62 \%$ of them had fair knowledge score regarding angina care. As regarding practice, $60 \%$ of the studied sample had fair level of practice. There was a significant difference between nurses'knowledge and their practice of care, as well as the statistical significant difference between characteristics of nurses (level of education, hierarchy, and experience years)and their knowledge level concerning care of theangina patient.

\section{Recommendations}

On the light of the current study, it is recommended,In-service educational program must be developed for nurses about care given to patient suffering from angina. Continuous supervision and evaluation as well as feedback of nurses' performance should be done regarding care of patient with angina in hospital to achieve and maintain the optimum quality of care. Standardized nursing procedure booklets and guidelines for the nurses should be available at the unit to guide them for giving the adequate care of patient with angina. Increasing the specialty of cardiovascular nursing with maintain effective continuing professional education. Provide incentives for nurses working in such units to raise the morale they have to continue to work in a satisfactory manner. Resolving nurses' shortage to decrease the nurse's workload is mandatory.

\section{References}

Abdelhamid, A., (2011). Assessment of nurses performance regarding angina attack patients in emergency unit at Mansoura University Hospitals. Master Thesis, Medical - Surgical Nursing, Faculty of Nursing, Zagazig University.

Abdelmoaty, N., (2009). Nurses' performance in caring for patients with cardiac arrest. Master Thesis, Faculty of Nursing, Ain Shams University. pp: 81-92.

Ahmed, A., (2013). Developing nursing care standards for patients with disectomy at Assuit University Hospital. Unpublished Master Thesis in Medical Surgical Nursing, Faculty of Nursing. p. 74.

Ahmed, G., Muhammed, Z., AbdElateef, M.,\&Ghanem, H., (2015). Coronary artery bypass grafting, effect of developing and implementing nursing care standards on patient's outcome. $J$ Am Sci 11:181-188.

Baeez, Y, Shakor, S., \& Ali, S.,(2019). Assessment of Nurses Staff Knowledge Regarding Chest Pain 
Nurses' Performance Regarding Caring etc...

Management and Respiratory Maintains in Cardiac Care Unit. Indian Journal of Public Health Research \& Development;10(10).

Bellchambers, J., Deane, S., \&Pottle, A., (2016). Diagnosis and management of angina for the cardiac nurse. $\mathrm{Br} J$ Card Nurs; $11: 324$.

Blanchard, J., \&Murnaghan, D., (2010). Nursing patients with acute chest pain: practice guided by the prince edward island conceptual model for nursing. Nurse EducPract; 10:48-51.

Chow, S., Chan, Y., Ho, S., \& Ng, K., (2017). Cardiac health knowledge and misconceptions among nursing students, implications for nursing curriculum design. $B M C$ Nurs; $16: 46-48$.

Collins, M., (2001). When your patient has an implementable cardioverter- defibrillator.Am J Nurses 94:44-48.

Drew, B., \&Krucoff , M., (2010). Multi lead ST-segment monitoring in patients with acute coronary syndromes: a consensus statement for healthcare professionals. Am J Crit Care; 8:372-386

El-Metwally, S., (2012). Effect of educational program on the performance of nurses working with coronary artery bypass grafting patients at Cardiac Care Unit at Nasser Institute Hospital, Un published doctorate thesis, Faculty of Nursing, Benha University.

Gaziano, T., Bitton, A., Anand, S., Abrahams-Gessel, S., \& Murphy, A., (2010).Growing epidemic of coronary heart disease in low and middle income countries. Current
Problems in Cardiology; 35:72115.

Hamed, S., (2009).Nurses performance during cardio-pulmonary resuscitation in Intensive Care Unit and Cardiac Care Unit at Benha University hospital.Master thesis, Faculty of Nursing, Benha University, Egypt, page 85.

Hart, P., Spiva, L. and Kimble, L., (2011). Nurses' knowledge of heart failure education principles survey: a psychometric study. Journal of Clinical Nursing, 20(21-22), pp.3020-3028.

Heart Foundation (2018).Angina (Brochure PDF). Auckland: Heart Foundation of New Zealand. https://www.heartfoundation.org.n z/shop/heart-healthcare/what-isangina-v4.pdf.

Ibrahim, R., Abd-Allah, K., Arafa, O., $\&$ Mohammed, S.,(2017).Effect of nursing care standards on nurses' performance in caring for patients with cardiac arrhythmias.Egyptian Nursing Journal;14(3), PP : 251258.

Mahdy, A., (2009). Effect of training program on staff nurses performance and empowerment toward care of patient undergoing organs and tissues transplantation. Doctorate thesis.Faculty of Nursing, Benha University. pp. 115-116

Mohammed, W.,(2016). Assessment of Nurse's Knowledge and Practice Regarding Care of Patients with Acute Coronary Syndrome in ElmakNimer University Hospital, Published master thesis in Medical -Surgical NursingScience, Faculty of Postgraduate and scientific research, ShendiUniversity,Sudan, pp. 55-62 
Mariam SabryShehab1,AmalEid et. al.

Motahediyantabrizi, E., NajafiMehri, S., Samiei, S., Einollahi, B., \&Babaei, G., (2009).Effect of programmed nursing care in prevention of hemodialysis complications.Critical Care Nurs;2(2):55-9.

Perry, A., Potter, P., \&Ostendorf, W. (2014). Clinical skills and nursing techniques (8 th ed.). St Louis, MO: Elsevier-Mosby.

Proehl, J., (2009). Emergency nursing procedures $\left(4^{\text {th }}\right.$ ed. $)$. St. Louis, Mo.: Saunders Elsevier.

Sakr, M., Metwaly, E. \&Taha, N.,(2019) .Effect of intervention guidelines on nursing performance

regarding patients with angina.Egyptian Nursing Journal;16:70-79

Siebens, K., Moons, P., Geest, S., Miljoen, H., Drew,B., \&Vrints, C., (2007). The role of nurses in a chest pain unit.Eur $J$ CardiovascNurs 6:265-272. Back to cited text no. 23

Taha, A. (2017). Impact of a designed teaching protocol about nursing management of coronary artery bypass grafting on nurse's knowledge, practices, and patient's outcome.Journal of Nursing and Health Science (IOSR-JNHS); 6(4) Ver. III, pp. 13-28. 